\title{
Correction: Kinetics of antibody responses to PfRH5-complex antigens in Ghanaian children with Plasmodium falciparum malaria
}

Frederica D. Partey, Filip C. Castberg, Edem W. Sarbah, Sarah E. Silk, Gordon A. Awandare, Simon J. Draper, Nicholas Opoku, Margaret Kweku, Michael F. Ofori, Lars Hviid, Lea Barfod

The affiliation for the eleventh author is incorrect. Lea Barfod is not affiliated with \#6 but with \#5 The Jenner Institute, University of Oxford, Oxford, United Kingdom.

\section{Reference}

1. Partey FD, Castberg FC, Sarbah EW, Silk SE, Awandare GA, Draper SJ, et al. (2018) Kinetics of antibody responses to PfRH5-complex antigens in Ghanaian children with Plasmodium falciparum malaria. PLoS ONE 13(6): e0198371. https://doi.org/10.1371/journal.pone.0198371 PMID: 29883485

\section{Gopenaccess}

Citation: Partey FD, Castberg FC, Sarbah EW, Silk SE, Awandare GA, Draper SJ, et al. (2018) Correction: Kinetics of antibody responses to PfRH5-complex antigens in Ghanaian children with Plasmodium falciparum malaria. PLOS ONE 13(9): e0204452. https://doi.org/10.1371/journal. pone.0204452

Published: September 17, 2018

Copyright: ๑ 2018 Partey et al. This is an open access article distributed under the terms of the Creative Commons Attribution License, which permits unrestricted use, distribution, and reproduction in any medium, provided the original author and source are credited. 